\title{
The Neglected Femoral Neck Fracture in Young Adults: Review of a Challenging Problem
}

\author{
Amit Roshan, MRCS and Shatrughna Ram, MCh (Orth), FRCS
}

\begin{abstract}
A neglected femoral neck fracture is one where there has been a delay of more than 30 days to seek medical help from the time of the original injury. Among the spectrum of femoral neck fractures, the neglected fracture in a young adult (age $<60$ years) is one of the most challenging to treat if femoral head salvage is attempted. The main complication is avascular necrosis (AVN) of the femoral head with most reported incidences being $<15 \%$ (range $0 \%$ to $67 \%$ ), which is similar to the complication rate with non-neglected femoral neck fractures.
\end{abstract}

This review consolidates our current knowledge about the problem, discusses the various treatment options and compares the published long-term results. There are no clear guidelines for management of neglected femoral neck fractures, although multiple methods have been used with varying success. Bone grafting or internal fixation in isolation does not provide a satisfactory outcome. Osteotomy has given better outcomes (AVN 6\% to 17\%, non-union $0 \%$ to $15 \%$ ), but mechanical changes at the femoral neck may lead to a persistent painful hip. Bone grafting with internal fixation has emerged as a reliable method with good long-term functional outcomes.

Keywords: Femoral neck; Neglected fracture; Young

I matter of urgency in young adults $($ age $<60)$ in an attempt to preserve the precarious blood supply of the femoral head. Some authors have presented such patients as a "vascular emergency" with operative intervention advised within 6 to 8 hours. ${ }^{1}$ While this time-capped figure is somewhat arbitrary, it emphasizes the importance of trying to preserve the femoral head in a young active patient.

Multiple reports identify a subset of these patients who have delayed presentation for medical treatment. ${ }^{2-5}$ While there is no defined lag period for such a fracture to be called "neglected," Myers et $\mathrm{l}^{6}$ introduced the term to indicate a delay of 30 days or more from the injury to seek medical help. We will use this definition for the purpose of this review.

Most early reports, before 1980, have been from developed countries and consisted of unrecognized fractures or those initially managed with a wait and watch policy, and in the

Reprint Requests: Amit Roshan, MRCS, Department of Plastic Surgery, Wythenshawe Hospital, Manchester M23 9LT, UK, Tel/Fax: +44-I772-522848, Email: amit.roshan@mac.com true sense of the term, the latter were not "neglected." $7-12$ Over the last 20 years, the distribution of published reports of this problem has shifted to developing countries, where the time before medical treatment sought may be several months because of poverty, ignorance, lack of facilities or faith in traditional bonesetters. ${ }^{2-5}$

The incidence of this injury is unknown, but the burden of disease is likely to be decreasing with improving healthcare facilities in developing countries. Published literature is sporadic and from ill-defined population groups. This is compounded by differing presentations to qualified medical treatment centers and under-reporting. Among the causes for this injury, high-energy injuries from road traffic accidents and falls from heights are most common. ${ }^{13}$ The financial burden to society is also considerable with patients tending to be economically active and the treatment lengthy and costly. With appropriate treatment, early return to function can be achieved. ${ }^{14}$
Received: January 29, 2007

Ist Revision: July 23, 2007 2nd Revision: October 15, 2007

Accepted: October 24, 2007

doi: $10.3|2| / \mathrm{cmr} .2008 .752$ 
Table 1. Neglected femoral neck fracture in young adults - a comparison of the literature.

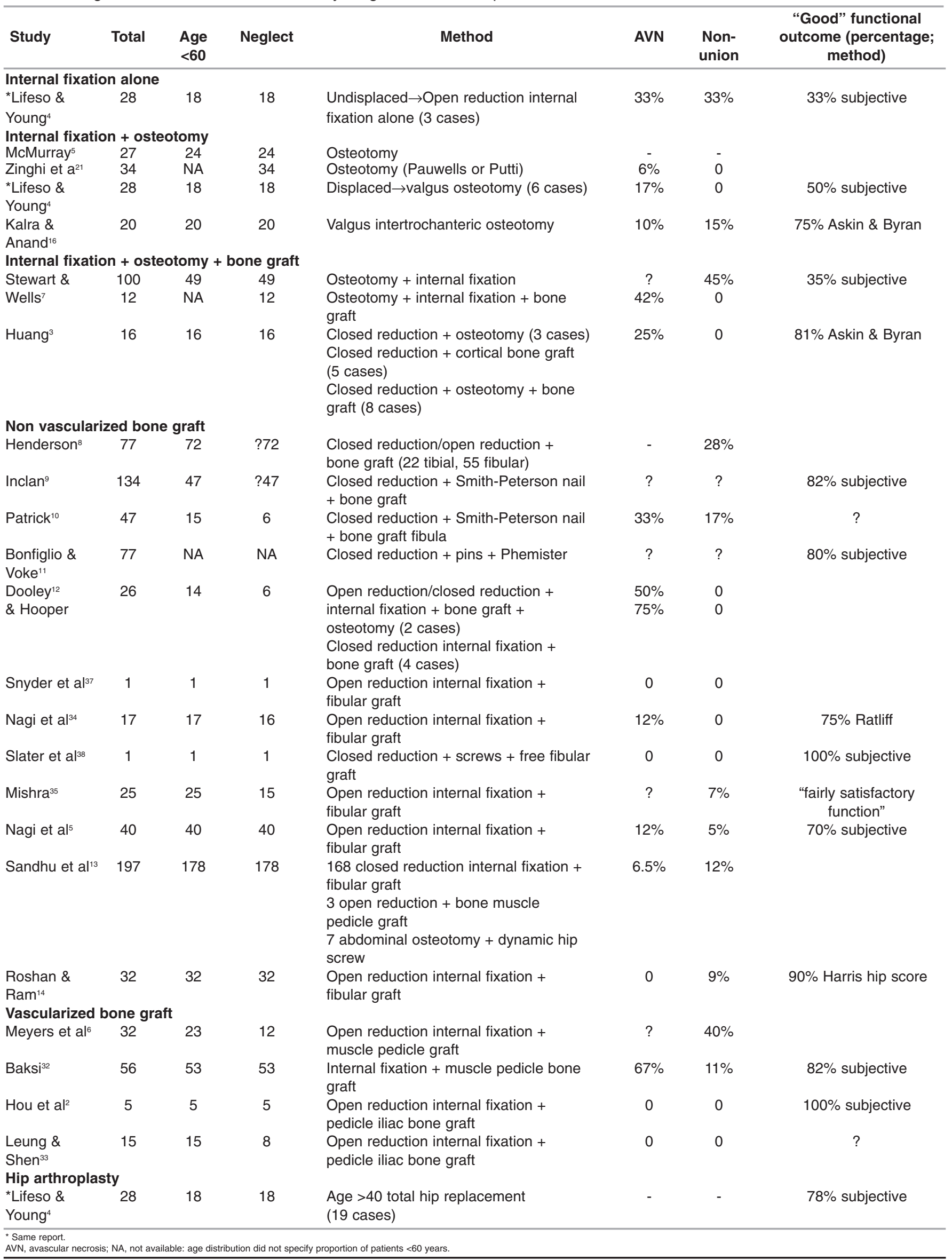




\section{Materials and Methods}

We performed a Medline search with the keywords "neglected fracture", "femoral neck" and "young" to identify published reports of this problem. We identified 22 reports in the English language that clearly identified neglected femoral neck fractures, as defined by Myers et al, ${ }^{6}$ in patients under the age of 60. A tabulation of the reports is summarized in table 1. Some papers had an age distribution extending beyond 60 and did not distinguish between these fractures on the basis of age. ${ }^{10,15,16}$ These reports have been included, but the exact numbers of patients under 60 have been omitted from the table. We discuss the various treatment options based on the identified papers and the reported success rates.

\section{Pathophysiology}

The blood supply to the femoral head has been traditionally described from three sources: ${ }^{17}$ (1) an extracapsular arterial ring located at the base of the femoral neck, (2) ascending cervical branches of the arterial ring on the surface of the femoral neck, and (3) arteries of the ligamentum teres.

Wertheimer et al ${ }^{18}$ studied the arterial supply of the femoral head in an angiographic and histologic study and concluded there was anastomosis between different arterial sources in $62 \%$ of the cases. However, even with these arterial rings, blood supply can easily be compromised, with intracapsular and intraosseous pressures exceeding diastolic blood pressure following injury. 19,20

Most femoral neck fractures, being intracapsular, have the additional problem of synovial fluid interfering with the healing process. ${ }^{21,22}$ As there is no periosteal layer, all healing is endosteal. Angiogenesis inhibiting factors in synovial fluid also can inhibit fracture repair. These factors, along with the precarious blood supply to the femoral head, make healing unpredictable and non-unions fairly frequent.

A meta-analysis of 106 reports of displaced femoral neck fractures treated early (i.e., non-neglected) gave figures of nonunion between $23 \%$ and $37 \%$ (95\% confidence interval [CI]), and a cumulative avascular necrosis (AVN) rate of $11 \%$ to $19 \%$ $(95 \% \mathrm{CI}) .{ }^{23}$ Some individual reports, however, claim a nonunion rate as low as $4 \%$, with many around $15 \%$. The AVN rate in this meta-analysis is likely to be underestimated, as segmental collapse does not occur universally. With early anatomical reduction and stable internal fixation, the incidence of non-union should be acceptably low, as blood supply improves with some vascular continuity being established.

Stromqvist et $\mathrm{al}^{24}$ used scintigraphy and pathologic analysis to assess vascularity of femoral heads at re-operation following failure of internal fixation and concluded that there was a genuine increase in vascularity later in the course of avascular heads, with the apical part of the femoral head sustaining maximum insult and being the slowest to revascularize. This would indicate that vascularity does improve with time, although the extent of this is unknown.
So why is AVN not universal to neglected fractures of the femoral neck? Soto-Hall et al ${ }^{25}$ suggested osteonecrosis was rare when treatment for femoral neck fracture was delayed. They postulated that patients inevitably assumed the position of greatest joint capacity (i.e., the hip being flexed, abducted and externally rotated), which in turn relieved intra-articular tamponade and lessened the possibility of osteonecrosis.

Reported incidence of AVN following neglected femoral neck fractures ranges between $0 \%$ to $67 \%$ (table 1) with most reports being $<15 \%$. The relationship between osteonecrosis and non-union is not fully understood. Early histological studies indicated that vascular insult to the femoral head might have a role to play in the healing. ${ }^{22,26}$ However, osteonecrosis is not necessary for the development of nonunion, as non-union may develop with a radiologically normal femoral head.

\section{Presentation}

A majority of these patients are young males in the age group 30 to 40 years with a unilateral hip injury. ${ }^{13,14}$ Most (up to $65 \%$ ) manage to walk with support but have painful restricted range of movements. The bed-bound patients (17.5\%) usually seek help earlier than the mobile patients. The remaining patients $(17.5 \%)$ can walk without aids and have reasonable functional capacity, even managing to squat and sit crosslegged. ${ }^{13,14}$ The remarkable amount of function that young adults often have with this injury is worth emphasizing. A relevant clinical history, including the original injury mechanism and subsequent treatment, is important. Metabolic history and other medical history may have a bearing on outcome, as may smoking. Duration of symptoms rarely has been an important factor in management.

Physical examination may reveal painful range of movement as an indicator of non-union, as can a painful limp. Limb length and rotational deformity assessment are important considerations.

\section{Diagnosis}

Uniplanar radiography remains the cornerstone of diagnosis. $^{5,14}$ Figure 1 and Figure 2 (panel A) illustrate typical features in a neglected femoral neck fracture. Apart from the appearances of a femoral neck fracture, usually Garden III or IV, there are usually signs of neglect including femoral neck resorption, femoral head osteoporosis and signs of AVN. ${ }^{27,28}$

On occasion, it may be difficult to assess the femoral neck, in which case computed tomography scans are effective to assess the fracture geometry. The need for this in neglected fractures is rarely necessary, as they are usually obvious.

Sandhu et $\mathrm{al}^{13}$ have proposed a radiological classification for this injury based on the following variables: (1) fracture site irregular or smooth, (2) size of proximal fragment $>2.5 \mathrm{~cm}$ or $<2.5 \mathrm{~cm}$, (3) gap between fragments $(<1 \mathrm{~cm}, 1 \mathrm{~cm}-2.5 \mathrm{~cm}$ or 


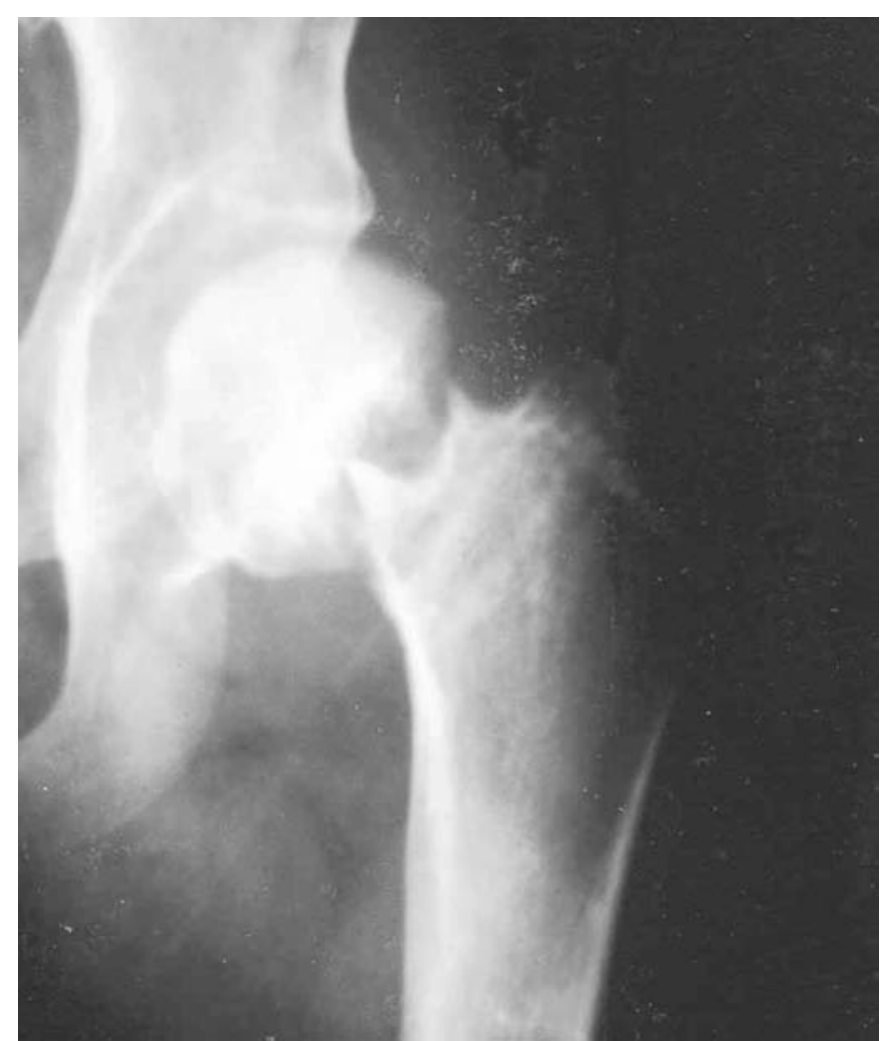

Figure 1. The typical features in a neglected femoral neck fracture. This view is with the hip in internal rotation and shows the femoral neck resorption clearly, with no avascular necrosis of the femoral head.

$>2.5 \mathrm{~cm}$ ), and (4) signs of AVN. This classification involves a magnetic resonance imaging scan for determination. It has not been validated and does not alter management.

Scintigraphy may have a role in early postoperative evaluation of AVN before plain radiographic features are identified. Bone scans performed within 2 weeks of operation following 306 non-neglected hip fractures have been shown to determine the healing course with an accuracy of 91\% (into categories of uneventful healing, hardware failure, non-union and AVN). ${ }^{29}$ Broeng et $\mathrm{al}^{30}$ demonstrated that decreased uptake noted on a bone scan 1 to 3 weeks postoperatively and 2 months postoperatively was indicative of eventual loss of reduction or segmental collapse in $50 \%$ of patients, whereas normal or increased uptake at those time periods correlated with uncomplicated healing in $90 \%$.

\section{Treatment Options}

There have been many studies regarding the management of neglected femoral neck fractures in young adults. All aim at preserving the femoral head with hip hemiarthroplasty being reserved as a salvage or secondary procedure. The treatment options tried have predominantly used internal fixation in conjunction with either osteotomy or bone grafting (vascularized or non-vascularized), with hip arthroplasty being a salvage procedure.
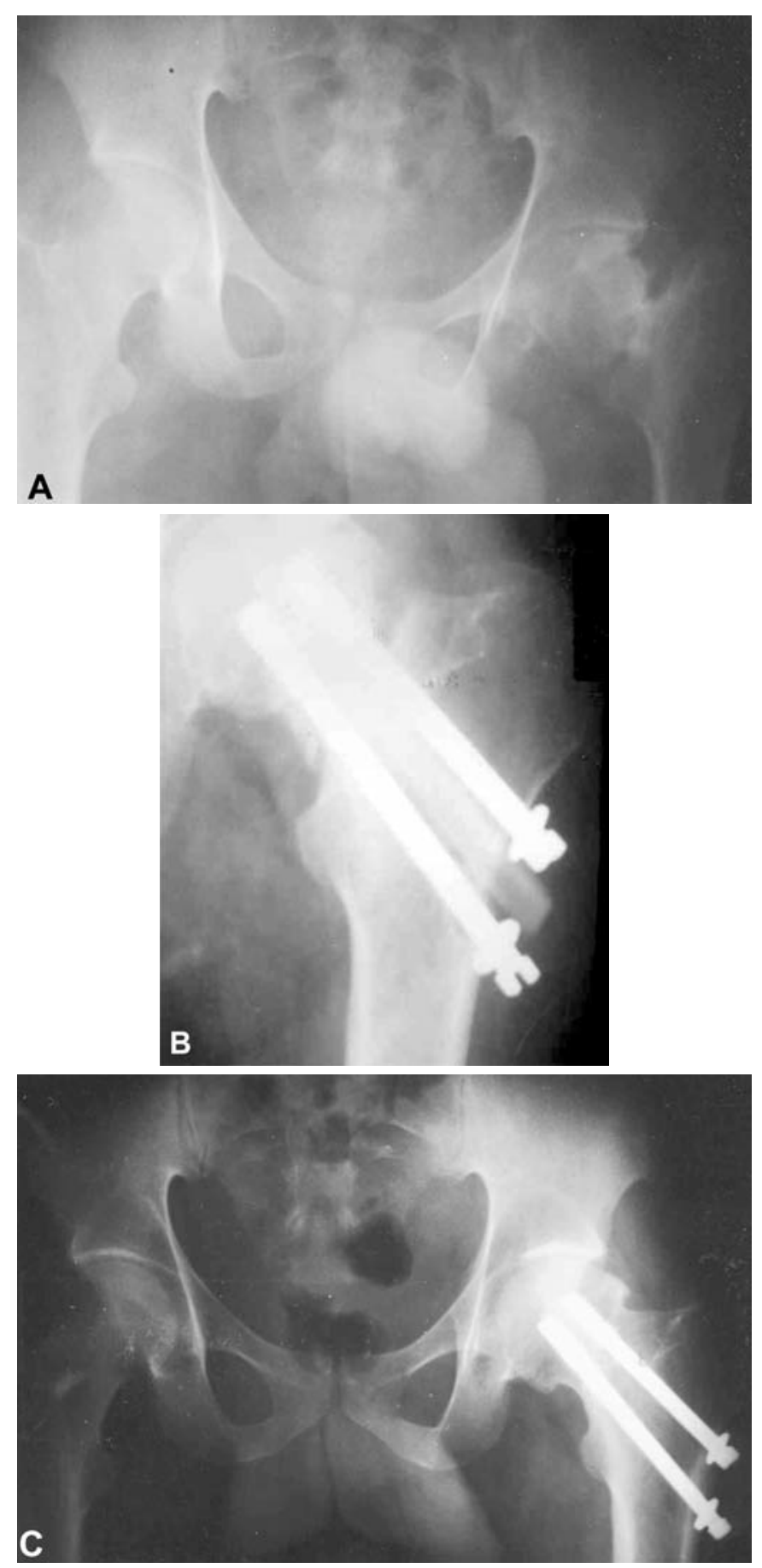

Figure 2. (A) A preoperative radiograph showing typical features of a neglected left femoral neck fracture with neck resorption, osteopenia and avascular necrosis in a 33-yearold man. (B) An early postoperative radiograph shows the femoral neck with two cannulated screws and fibular graft insertion. (C) A long-term follow up radiograph taken 4.5 years postoperatively shows good bony union. Harris hip score at this stage was 84.

Figure 3 illustrates the various treatment options in this setting. Table 1 summarizes the various studies done in this field and their comparative outcomes. 


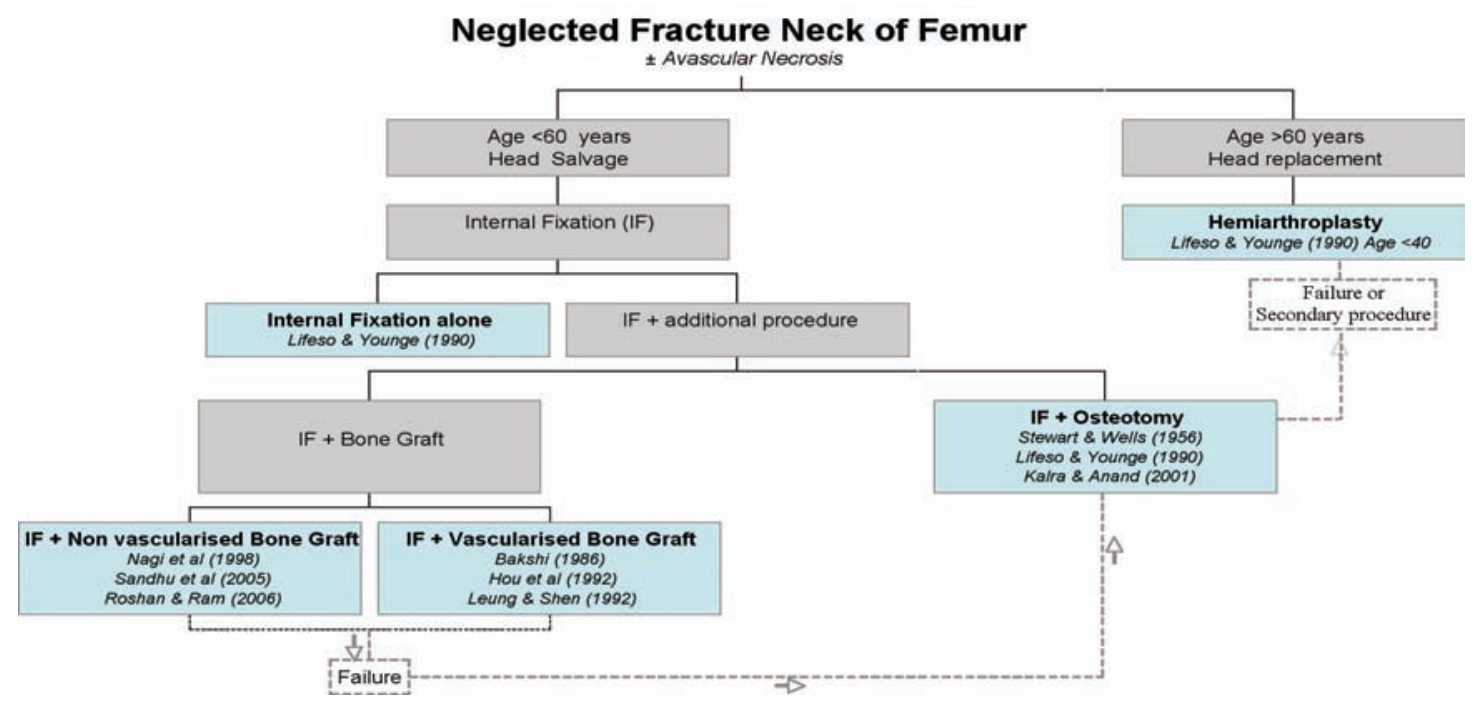

Figure 3. The treatment options available in the neglected femoral neck fracture of a young adult. The indicative studies mentioned are compared with others in table 1.

\section{Internal Fixation Alone}

Internal fixation alone is seldom performed in the neglected femoral neck fracture. Lifeso and Younge ${ }^{4}$ used this method in 3 of their 28 young patients with neglected femoral neck fractures, in those with undisplaced fractures, with one patient developing $\mathrm{AVN}$ and another non-union. Although it is the simplest of procedures, it does not address either the altered mechanics of shortening, or the biology of neglect and bone healing.

\section{Internal Fixation and Osteotomy \pm Bone Grafting}

Osteotomy has been used to alter biomechanics at the fracture site to promote healing, both with or without internal fixation, and in some cases with the addition of bone grafting to help stimulate bone healing.

The two main types of osteotomy used have been the medial displacement osteotomies, such as that employed by McMurray, ${ }^{15}$ and the angulation osteotomy such as employed in studies by Kalra and Anand. ${ }^{16}$ The valgus angulation osteotomy is usually of the subtrochanteric or intertrochanteric type, and is more efficient than the displacement osteotomy in converting the shearing forces at the fracture site into compression forces, thereby improving union chances. In addition, the angulation osteotomy can correct rotational and limb length discrepancies at the same time.

However, osteotomy has two important problems. First, shortening, limp and a decreased range of movement are common, probably because of increased pressures on the femoral head leading to degenerative disease or osteonecrosis. ${ }^{15,31}$ Secondly, there are potential risks of nonunion at the osteotomy site, although this has not been common in the literature. 4,8
The results of the osteotomy when used have resulted in rates of AVN ranging between $6 \%$ and $42 \%$ and a non-union rate between $0 \%$ and $45 \%$ (table 1). It is difficult to compare the functional outcome of these studies, as the criteria used are subjective and variable (modified Askin and Byran,3,16 subjective evaluation ${ }^{4,7}$ or no long-term functional followup ${ }^{15,31}$ ). Where measured by differing criteria, a "good" functional outcome has been recorded in $35 \%$ to $80 \%$ of the subject population.

\section{Internal Fixation and Bone Grafting}

Bone grafting has been the most widely used method to address the problem of the neglected femoral neck fractures, and both vascularized and non-vascularized bone grafts have been used with often excellent results. Henderson ${ }^{8}$ had employed non-vascularized bone grafting alone in 72 patients with a non-union rate of $28 \%$, but this procedure has been largely abandoned in favor of combination procedures with internal fixation at the same time.

Various types of bone grafts have been used to address this problem. Vascularized grafts include muscle pedicle or vascular pedicle grafts while non-vascularized grafts include Phemister-type cortical tibial grafts and free fibular strut grafts.

Meyers et $\mathrm{al}^{6}$ and $\mathrm{Baksi}^{32}$ have employed vascularized grafts using muscle pedicle grafts in separate studies involving patients with a delay of more than 3 months. Unfortunately, the blood supply with this construct is unreliable, and there was a high incidence of non-union. In contrast, vascularized pedicle grafts using either the iliac crest or the fibula have shown excellent results with union rates of $91 \%$ to $100 \%$ in small series. ${ }^{2,33}$ However, this technique is highly technical and requires microsurgical facilities and experience. 
Free fibular grafting has been widely studied as a method to introduce both structural support and a graft framework in a neglected femoral neck fracture. $5,13,14,34,35$ The results with this procedure have given non-union rates between $0 \%$ to $17 \%$ and AVN rates of $0 \%$ to $33 \%$. This is our preferred method, and 28 patients in our own case series had an average Harris hip score of 87.1 at a mean follow-up of over 6 years. ${ }^{14}$ Figure 2 demonstrates the progression of a neglected femoral neck fracture treated through this method. The free fibular graft has the advantages of being technically simple with minimal donor site morbidity, providing additional rotational stability because of the trifin shape of the graft itself, and the medullary canal of the graft allowing a guide pin insertion for ease of introduction.

\section{Hip Arthroplasty}

Hip replacement arthroplasty has been reserved as a secondary salvage procedure. In the setting of neglected femoral neck fractures in the young adult, only one study has reported hip arthroplasty in 19 cases. ${ }^{4}$ This study classified outcome as good or poor soon after the initial operation based on non-standardized criteria (i.e., not requiring further surgery, ambulatory in the community, discharged home, healed within 3 months, minimal pain.)

\section{Discussion}

The neglected femoral neck fracture in young adults is among the most difficult to treat in the spectrum of femoral neck fractures. Dickson's epithet of the "unsolved fracture" is especially applicable.

Attempts at head salvage in the young are important. Bone grafting or internal fixation in isolation has not provided predictable satisfactory outcomes. Osteotomy has been used with better outcomes in this group of patients (AVN 6\% to $17 \%$, non-union rates $0 \%$ to $15 \%$ ), but the functional results are modest because of the frequency of a persistent painful limp due to the mechanical changes at the femoral neck.4,15,16 Bone grafting has emerged as a reliable method to treat these fractures with good functional outcomes in the long-term. Our preference is for a free fibular graft with two cannulated screws, and early mobilization (AVN $0 \%$ to $6.5 \%$, non-union $9 \%$ to $12 \%) .13,14$

In his 1953 Presidential address to the American Orthopaedic Association, Dickson made a plea to avoid a "defeatist attitude" in sacrificing the femoral head in favor of advancing replacement technology. This plea is still as relevant over 50 years down the line. ${ }^{36}$

\section{References}

1. Swiontkowski MF, Winquist RA, Hansen ST Jr. Fractures of the femoral neck in patients between the ages of twelve and forty-nine years. J Bone Joint Surg Am 1984;66:837-846.

2. Hou SM, Hang YS, Liu TK. Ununited femoral neck fractures by open reduction and vascularized iliac bone graft. Clin Orthop Relat Res 1993;(294):176-180.
3. Huang $\mathrm{CH}$. Treatment of neglected femoral neck fractures in young adults. Clin Orthop Relat Res 1986;(206):117-126.

4. Lifeso R, Younge D. The neglected hip fracture. J Orthop Trauma 1990;4:287-292.

5. Nagi ON, Dhillon MS, Goni VG. Open reduction, internal fixation and fibular autografting for neglected fracture of the femoral neck. J Bone Joint Surg Br 1998;80:798-804.

6. Meyers MH, Harvey JP Jr, Moore TM. Treatment of displaced subcapital and transcervical fractures of the femoral neck by muscle-pedicle-bone graft and internal fixation. A preliminary report on one hundred and fifty cases. J Bone Joint Surg Am 1973;55:257-274.

7. Stewart MJ, Wells RE. Osteotomy and osteotomy combined with bone-grafting for non-union following fracture of the femoral neck. J Bone Joint Surg Am 1956;38-A:33-48.

8. Henderson MS. Ununited fractures of the neck of the femur treated by aid of the bone graft. J Bone Joint Surg 1940;22:97-106.

9. Inclan A. Late complications in fractures of the neck of the femur treated by nailing, bone graft or both. J Internat Coll Surg 1946;9:36-50.

10. Patrick J. Intracapsular fractures of the femoral neck treated with a combined Smith-Peterson nail and fibular graft. J Bone Joint Surg 1949;31:67-80.

11. Bonfiglio M, Voke EM. Aseptic necrosis of the femoral head and non-union of the femoral neck: effect of treatment by drilling and bone graft (Phemister technique). J Bone Joint Surg 1968;50A:48-66.

12. Dooley BJ, Hooper J. Fibular bone grafting for non union of fracture of the neck of the femur. Aust N Z J Surg 1982;52:134-140.

13. Sandhu HS, Sandhu PS, Kapoor A. Neglected fractured neck of the femur: a predictive classification and treatment by osteosynthesis. Clin Orthop Relat Res 2005;(431):14-20.

14. Roshan A, Ram S. Early return to function in young adults with neglected femoral neck fractures. Clin Orthop Relat Res 2006;447:152-157.

15. McMurray TP. Ununited fractures of the neck of the femur. J Bone Joint Surg 1936;18:319-327.

16. Kalra M, Anand S. Valgus intertrochanteric osteotomy for neglected femoral neck fractures in young adults. Int Orthop 2001;25:363-366.

17. Crock HV. An atlas of the arterial supply of the head and neck of the femur in man. Clin Orthop Relat Res 1980;(152): $17-27$.

18. Wertheimer LG, Lopes Sde L. Arterial supply of the femoral head. A combined angiographic and histological study. J Bone Joint Surg Am 1971;53:545-556.

19. Crawfurd EJ, Emery RJ, Hansell DM, Phelan M, Andrews BG. Capsular distension and intracapsular pressure in subcapital fractures of the femur. J Bone Joint Surg Br 1988;70: 195-198.

20. Harper WM, Barnes MR, Gregg PJ. Femoral head blood flow in femoral neck fractures. An analysis using intra-osseous pressure measurement. J Bone Joint Surg Br 1991;73:73-75.

21. Kregor PJ. The effect of femoral neck fractures on femoral head blood flow. Orthopedics 1996;19:1031-1036.

22. Banks HH. The healing of intra-articular fractures. Clin Orthop Relat Res 1965;40:17-29.

23. Lu-Yao GL, Keller RB, Littenberg B, Wennberg JE. Outcomes after displaced fractures of the femoral neck. A meta-analysis of one hundred and six published reports. J Bone Joint Surg Am 1994;76:15-25.

24. Stromqvist B, Hansson LI, Palmer J, Thorngren KG. Femoral head vitality at reoperation for femoral neck fracture complications. Arch Orthop Trauma Surg 1984;103:235-240. 
25. Soto-Hall R, Johnson LH, Johnson RA. Variations in the intra-articular pressure of the hip joint in injury and disease. A probable factor in avascular necrosis. J Bone Joint Surg Am 1964;46:509-516.

26. Banks HH. Factors influencing the result in femoral neck fractures. J Bone Joint Surg 1962;44A:931-964

27. Martel W, Sitterley BH. Roentgenologic manifestations of osteonecrosis. Am J Roentgenol Radium Ther Nucl Med 1969;106:509-522.

28. Nordkild P, Sonne-Holm S. Necrosis of the femoral head following fracture of the femoral neck. Injury 1986;17: 345-348.

29. Stromqvist B, Kelly I, Lidgren L. Treatment of hip fractures in rheumatoid arthritis. Clin Orthop Relat Res 1988;(228): 75-78.

30. Thorngren KG, Ceder L, Svensson K. Predicting results of rehabilitation after hip fracture. A ten-year follow-up study. Clin Orthop Relat Res 1993;(287):76-81.

31. Zinghi GF, Specchia L, Ruggieri N, Galli G. The role of osteotomy in the treatment of pseudarthrosis of the neck of the femur in younger patients. Ital J Orthop Traumatol 1985;11:341-348.

32. Baksi DP. Internal fixation of ununited femoral neck fractures combined with muscle-pedicle bone grafting. J Bone Joint Surg Br 1986;68:239-245.

33. Leung PC, Shen WY. Fracture of the femoral neck in younger adults. A new method of treatment for delayed and nonunions. Clin Orthop Relat Res 1993;(295):156-160.

34. Nagi ON, Dhillon MS, Gill SS. Fibular osteosynthesis for delayed type II and type III femoral neck fractures in children. J Orthop Trauma 1992;6:306-313

35. Mishra D. Femoral neck fracture open reduction Asnis screw fixation and fibular grafting. Ind J Orthop 1998;32:32-35.

36. Dickson JA. The "unsolved" fracture: A protest against defeatism. J Bone Joint Surg Am 1953;35:805-822.

37. Snyder SJ, Sherman OH, Hattendorf K. Nine-year functional nonunion of a femoral neck stress fracture: treatment with internal fixation and fibular graft. A case report. Orthopedics 1986;9:1553-1557.

38. Slater RN, Gore R, Slater GJ. Free fibular bone grafting for femoral neck fractures: precise graft placement using a 'cannulated screw' technique. J R Coll Surg Edinb 1993;38:376-377.

\section{Author Affiliations}

Amit Roshan, MRCS

Department of Plastic Surgery

Wythenshawe Hospital

Manchester, M23 9LT

United Kingdom

Shatrughna Ram, MCh (Orth), FRCS

Advanced Orthopaedic Centre

Patna, India 800016 